\title{
EL MUSEO DE LA MEMORIA Y EL MUSEO NACIONAL DE COLOMBIA: EL ARTE DE EXPONER NARRATIVAS SOBRE EL CONFLICTO ARMADO INTERNO
}

\section{REMEMBRANCE MUSEUM AND NATIONAL MUSEUM OF COLOMBIA: THE ART OF EXPOSING NARRATIVES ABOUT THE INTERNAL ARMED CONFLICT}

\section{MUSEU DA MEMORIA E MUSEU NACIONAL DA COLÔMBIA: A ARTE DE EXPOR NARRATIVAS SOBRE O CONFLITO ARMADO INTERNO}

\author{
Páginas Ana Guglielmucci \\ 10-29 anagugliel74@gmail.com
}

Recibido

21 de octubre de 2015

Aceptado 30 de octubre de 2015
Doctora en Antropología de la Universidad de Buenos Aires, Investigadora Adjunta del CONICET y docente del Departamento de Antropología, Facultad de Filosofía y Letras, UBA. Ha realizado una estancia posdoctoral en el Departamento de Antropología, Facultad de Ciencias Sociales, Universidad de los Andes. Ha publicado los libros La consagración de la memoria. Una etnografía acerca de la institucionalización del recuerdo sobre el terrorismo de Estado en la Argentina (2013) y Memorias desveladas: prácticas y representaciones colectivas del encierro por razones políticas (2007). Y ha editado el libro Vivir para contarlo: violencias y memorias en América Latina (2015), junto a Mg. Sigifredo Leal Guerrero. También ha publicado numerosos capítulos de libro y artículos en revistas académicas y de divulgación general.

Artículo derivado de la investigación postdoctoral financiada por el Consejo Nacional de Investigaciones Científicas y Técnicas de Argentina (2014-2015) titulada: "La construcción de representaciones sociales en torno al Estado-Nación: conmemoraciones, museos y sistemas de información. Un análisis comparativo entre Argentina y Colombia”. 


\section{Resumen}

Este trabajo se orienta a reflexionar sobre dos procesos museológicos: la renovación del Museo Nacional de Colombia, centrada en la sala Memoria y Nación, y la proyección del Museo

Nacional de la Memoria Histórica (MNMH) en el marco de un conflicto armado interno y un proceso de negociación de paz entre el gobierno del presidente Juan Manuel Santos y la guerrilla de las Fuerzas Armadas Revolucionarias de Colombia. A partir de un trabajo etnográfico realizado en la ciudad de Bogotá durante los años 2014 y 2015, analizo algunos de los dilemas museográficos que han surgido en diferentes contextos sociales cuando se busca mostrar o representar procesos históricos de violencia que han marcado de forma determinante a una nación.

\section{Palabras clave}

Violencia, museo de la memoria, Colombia 


\section{Abstract}

The aim of this paper is to reflect about two museological processes: the renovation of the National Museum of Colombia, focused on Memory and Nation room, and the projection of the National Museum of Historical Memory ( MNMH ) in the context of an internal armed conflict and peace negotiation process between the government of President Juan Manuel Santos and the guerrillas of the Revolutionary Armed Forces of Colombia. Based on an ethnographic work in Bogotá during the years 2014 and 2015, I discuss some of the museographical dilemmas that have emerged in different social contexts when it seeks to show or represent historical processes of violence that have marked a nation in a decisive way.

\section{Key words}

Violence, memorial museum, Colombia

\section{Resumo}

Este trabalho tem como objetivo refletir sobre dois processos museológicos: a renovação do Museu Nacional da Colômbia, centrada na galeria Memória e Nação, e na projeção do Museu Nacional da Memória Histórica (MNMH) no contexto de um conflito armado interno e o processo de negociação de paz entre o governo do presidente Juan Manuel Santos e a guerrilha das Forças Armadas Revolucionárias da Colômbia. Partindo de um trabalho etnográfico na cidade de Bogotá, durante os anos de 2014 e 2015, analiso alguns dos dilemas museográficos que surgiram em diferentes contextos sociais quando se pretende mostrar ou representar processos históricos de violência que marcaram decisivamente a nação.

\section{Palavras-chave}

Violência, museu da memoria, Colômbia 
"Jamás se da un documento de cultura sin que lo sea a la vez de la barbarie". (Benjamin, 1973, p. 182).

Los museos nacionales, desde la construcción de los Estados-Nación modernos, han tenido un importante rol en el registro y la narración de la historia de los nacientes países. En ellos, generalmente, se coleccionan y conservan objetos, se inscriben relatos y se hacen displays y recorridos donde se resignifican eventos que son presentados como los pilares de la nación. En ellos se procura almacenar y mostrar la memoria sobre el pasado desde el tiempo presente de la nación. En este sentido, el Museo Nacional de Colombia (MNC) se ha planteado como un espacio social y cultural que da cuenta del pasado y del presente nacional ${ }^{1}$. Sobre esta base, en este trabajo realizo una reflexión sobre el proceso de renovación del MNC, centrándome en la sala Memoria y Nación, y en los debates llevados adelante hasta ahora para el diseño y construcción del Museo Nacional de la Memoria Histórica (MNMH) en el marco de un conflicto armado interno que lleva más de cincuenta años y de un proceso de negociación de paz entre el gobierno del presidente Juan Manuel Santos y la guerrilla de las Fuerzas Armadas Revolucionarias de Colombia (FARC). ${ }^{2}$

Esta reflexión sobre la renovación y creación de iniciativas museísticas que refieren a la historia o la memoria histórica nacional en el marco de un conflicto armado interno se fundamenta en un trabajo etnográfico realizado en la ciudad de Bogotá durante los años 2014 y 2015. Durante este tiempo hice una serie de visitas y participé en las reuniones sostenidas por diversos actores vinculados al Centro Nacional de Memoria Histórica (CNMH) y recopilé material documental y periodístico en torno al rol de los museos en la construcción de narrativas sobre el conflicto armado colombiano. La información recolectada me permitió analizar los dilemas museográficos que han surgido en diferentes contextos cuando se busca mostrar o representar procesos históricos de violencia que han marcado de forma determinante a una nación.

1 El MNC es el más antiguo museo de Colombia, ubicado en la ciudad capital, abrió sus puertas en 1824. Su colección de arte colombiano, latinoamericano y europeo incluye pinturas, dibujos, grabados, esculturas, instalaciones y artes decorativas desde el período colonial hasta la actualidad. Ocupo distintas sedes, hasta instalarse en el inmueble actual que, originalmente fue la Penitenciaría central de Cundinamarca, conocida como el Panóptico. Durante casi dos siglos su misión ha sido la conservación y divulgación de testimonios representativos de los valores culturales de la Nación. Actualmente el museo se encuentra en una etapa de renovación. Véase "Repensar el Museo Nacional de Colombia” (2015). Recuperado de http://www.museonacional.gov.co/ sitio/renovacion/default.aspx

2 Este conflicto interno se ha caracterizado por una serie de enfrentamientos armados entre diferentes actores a lo largo de la historia nacional, lo que ha afectado particularmente a los sectores rurales que han sido víctimas de muertes, abusos y en muchos casos han debido desplazarse forzadamente de una región a otra. Desde la llamada guerra de los Mil Días entre los partidos Liberal y Nacional a fines del siglo XIX, los enfrentamientos entre conservadores y liberales a mitad del siglo XX, el bandolerismo, la creación de guerrillas rurales y urbanas y de grupos paraestatales, y la consolidación del narcotráfico, Colombia se ha visto surcado por conflictos regionales y guerras civiles. Para mayor información, véase Sánchez \& Meertens (1983). 


\section{El Museo como reservorio y agente de cambio}

En estas últimas décadas la memoria se ha vuelto objeto de la museología en varios países de Latinoamérica que han atravesado dictaduras, guerras o conflictos armados internos. En Argentina, Colombia, Chile, Perú y Uruguay, algunos sectores de la población y del gobierno han impulsado la creación de museos o espacios de la memoria para promover el conocimiento de lo sucedido durante ciertos períodos históricos signados por enfrentamientos violentos y su transmisión a las futuras generaciones con la finalidad de que tales eventos no se repitan. Además de ser pensados como mecanismos de reparación simbólica para las víctimas en el marco de procesos de justicia transicional. Así, con menores o mayores controversias públicas, las memorias del pasado reciente, o, de un pasado que no termina de pasar, se han convertido en un componente de nuestro patrimonio cultural y de los dispositivos museográficos actuales.

Respecto a esta incorporación de la memoria como objeto de estudio, conservación y promoción museográfica, Andreas Huyssen (2002) ha expresado una inquietud que continúa resonando sobre la expansión de las culturas de la memoria en sus variados contextos nacionales y regionales. Ante la amenaza del olvido que plantea la obsolescencia programada, el achicamiento del tiempo presente y un futuro incierto sin grandes utopías libertarias, pareciera que los recuerdos del pasado conservados en los museos fueran un importante reservorio de estabilidad y esperanza, pues parecieran proveer formas tradicionales de identidad cultural al sujeto moderno desestabilizado por la pérdida de una tradición viva, nacional o comunitaria. Pero, ¿hasta qué punto este tipo de iniciativas conmemorativas pueden garantizar una estabilidad cultural o la memoria de un evento socialmente traumático a lo largo del tiempo ante el torbellino cada vez más veloz de circulación de información, imágenes e historias? O, ¿de qué manera el pasado puede funcionar como una fuente de enseñanza que prevenga posibles catástrofes futuras cuando las tragedias no se repiten necesariamente de la misma manera? Otro tipo de inquietudes respecto a los museos pueden ligarse a las observaciones de Friedrich Nietzsche en su obra "Sobre la utilidad y el perjuicio de la historia para la vida [II Intempestiva]” (1874) en torno a la relación entre la historia y la vida o más bien la utilidad de la omnipotencia y el peso del pasado para la vitalidad del presente ${ }^{3}$. Por ejemplo, ¿cuál es el límite saludable y justo entre conservación y cambio, entre tradición e innovación, entre olvido y memoria?

Esta preocupación también ha sido expresada en numerosas ocasiones por grupos de personas que han promovido la creación de iniciativas conmemorativas como monumentos o espacios para la memoria. Por ejemplo, en Buenos Aires, tanto la creación del Monumento a las víctimas del terrorismo de Estado como del Museo o Espacio para la Memoria en el ex centro clandestino de detención (CCD) ESMA, ha generado una serie de debates en torno a la musealización y monumentalización de la memoria de las personas detenidas-desaparecidas y asesinadas. Si bien se ha considerado fundamental preservar el recuerdo de los crímenes cometidos por las agencias estatales y conmemorar a los ausentes forzados, uno de los principales temores enunciados frente a este tipo de iniciativas ha sido que ello podría acarrear la fosilización de la memoria en vez de mantenerla como un componente vivo que continúe abriendo preguntas sobre el presente; o, que el fenómeno de la violencia interna podría quedar

3 Ramos y Bernardez (2009) resumen la perspectiva de Nietzsche de la siguiente manera: "A la Historia, ese pasado omnipotente y con mayúsculas, Nietzsche la juzga a la luz de su utilidad para el presente y más precisamente para la vida presente. Pero la Historia y la vida en algún punto se antagonizan: la Historia es contemplación de lo pasado y la vida es actividad, fuerza, intensidad y emergencia de lo actual. La Historia, para Nietzsche, invade simbólicamente el alma y la inteligencia de los hombres, mediante el ejemplo y la grandeza de las glorias pasadas (la 'historia monumental'), la admiración de lo que la 'rutina ha admirado' ('la historia anticuario') o el juicio y la condena del pasado ('la historia crítica')” (p.2). 
Ana Guglielmucci

confiscado como un problema del pasado en vez de convertirse en una cuestión para prevenir su posible ocurrencia futura. A ello podría agregarse también el debate en torno a la conservación de las marcas edilicias y simbólicas como lugares de represión y muerte y la refuncionalización de estos mismos espacios como lugares de memoria, militancia y vida (Guglielmucci, 2013, p. 285).

En esta misma línea de discusión, en el campo específico de la museología moderna, la crítica a los museos tradicionales ha señalado que éstos deberían pensar en mayor medida en su rol como agentes de cambio de las sociedades y no únicamente en la conservación de los objetos de sus colecciones. Pero esta tensión entre conservar y transformar ha sido difícil de resolver en la concreción de iniciativas puntuales, ya sea para reformar los museos históricos nacionales o crear los nuevos espacios para la memoria histórica sobre traumas recientes. En el caso de Colombia, ello se ha hecho explícito tanto en los debates sostenidos por las diversas directoras y las curadoras del Museo Nacional en torno al cambio de guión general así como en las exposiciones para el bicentenario de la Independencia de la corona española o el intento de incluir una serie de muestras vinculadas con el conflicto armado interno, como la toma del Palacio de Justicia por el Movimiento 19 de abril (M-19) y la retoma por parte de las Fuerzas militares en 1985 o, la vida y la muerte del líder guerrillero Carlos Pizarro Leongómez (muestra titulada Hacer la paz en Colombia "Ya vuelvo", Carlos Pizarro, del 9 de septiembre del 2010 al 27 de febrero del 2011)4.

\footnotetext{
4 El M-19 fue una guerrilla urbana, conformada en 1974 por ex militantes de la Alianza Nacional Popular (ANAPO), el Partido Comunista Colombiano (PCC) y disidentes de las Fuerzas Armadas Revolucionarias de Colombia (FARC). Su acción más polémica tuvo lugar el 6 de noviembre de 1985, cuando un comando tomó el Palacio de Justicia, a lo que le siguió la retoma por parte del Ejército Nacional colombiano y el incendio del edificio, la biblioteca, parte de los archivos y la pérdida de la vida de más de 100 personas que estaban adentro (Leal Guerrero \& Gómez Angarita, 2013, p. 155). Varios detenidos sacados con vida del edificio ese día continúan desaparecidos. Durante el Gobierno de Barco (1986-1990), el M-19 participó de un proceso de paz que culminó en su desarme, desmovilización e ingreso en la vida civil mediante su participación en la contienda electoral. El actual alcalde de Bogotá, Gustavo Petro, fue miembro de este grupo.
}

Por lo general, tanto los museos como los monumentos nacionales no se ocupaban de exponer los conflictos internos que han hecho parte integral de las sociedades que dicen representar. Ellos presentaban la visión de los vencedores sin dar cuenta del punto de vista de los vencidos, a través de una serie de objetos que mostraban la supuesta supremacía no sólo militar sino también cultural de unos sobre otros. Además desplegaban una visión heroica y ejemplarizante centrada en la figura de los gestores de la patria. Este tipo de relato ha sido objetado por sectores de la comunidad nacional que fueron subordinados o marginalizados dentro del territorio, cuyas demandas fueron contempladas en las reformas constitucionales de la década del noventa y en los festejos del bicentenario desarrollados en algunos países de Latinoamérica. Así, los museos, han sido parte de controversias más amplias, ligadas, por un lado, a las disputas sociales y jurídicas por el reconocimiento de los derechos de las llamadas minorías o grupos étnicos, culturales, religiosos, políticos, de género, no hegemónicos; y por otro lado, a una serie de reflexiones académicas en torno a la relación entre historia, memoria y nación, como los trabajos de Pierre Nora (1989) sobre Les lieux de memoire -lugares donde se cristaliza y se refugia la memoria colectiva- que postularon una propuesta historiográfica novedosa para el estudio de la memoria y del presente y llevaron a repensar la función de esta ciencia en la nacionalización de la sociedad francesa. Pues, "como en otros países occidentales, la historiografía francesa se caracterizó por estar íntimamente ligada a las llamadas construcciones imaginarias de la nación” (Allier Montaño, 2008, p. 167). Todas estas controversias llevaron a una extendida revisión de las formas en que las naciones, sus poblaciones, culturas y territorios eran representadas por medio de dispositivos de comunicación como los manuales escolares, los programas de investigación social y los museos, entre otros.

El debate sobre la transformación de los museos y monumentos nacionales no ha sido simple y aún 
continúa. Los propios impulsores de estos cambios mencionan las resistencias existentes al interior de las propias instituciones y por parte del público para instalar nuevos sentidos que lleven a repensar el MNC o a rever cuáles son los relatos de nación que se quieren contar y qué tipo de nación se quiere incluir en esas narraciones, ya sea de un modo explícito o tácito. Respecto a estas intenciones de cambio, Cristina Lleras, ex curadora del Museo Nacional de Colombia, ha revelado que muchas personas han reclamado la restitución de las memorias heroicas de la Independencia, sobre todo a raíz de la conmemoración del Bicentenario colombiano, pero que, en el contexto de un conflicto armado interno que lleva más de cincuenta años, el Museo merece servir como una plataforma para reflexionar sobre otras memorias que no pueden ser ignoradas y que deben ser construidas entre todos los ciudadanos. En sus propias palabras: "Cabe mejor preguntarse sobre qué hechos 0 actores quiere hacerse memoria” y, "qué tipo de Museo puede representar a los colombianos" (Lleras Figueroa, 2008)

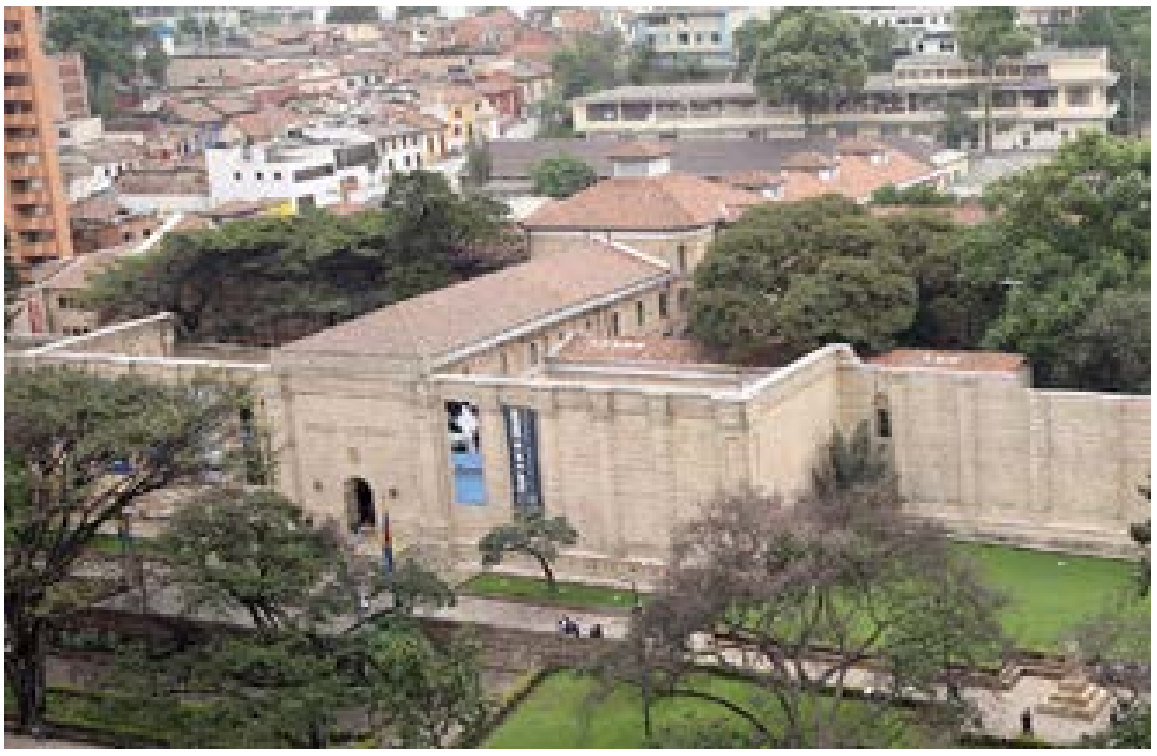

Figura 1. Fotografía del MNC (Peláez, 2015).

Esta situación conflictiva sobre lo que es o no es un museo nacional (un gabinete de investigación, un espacio comunicador y didáctico, un escaparate, entre otras representaciones posibles) y lo que debe conservarse y transmitirse en él, se puso de manifiesto en el MNC a raíz de la exposición del Bicentenario, realizada en el año 2010. Entre otras iniciativas, desde la dirección del Museo se invitó al artista cartagenero Nelson Fory a intervenir con unas pelucas afro a las estatuas de los próceres de la Independencia, como Bolívar o Santander, lo cual causó cierta polémica. A pesar de que la gente hacía fila para tomarse fotos con los próceres y su nuevo look, las críticas no se demoraron en llegar. Algunas personas interpretaron esto como una burla hacia los héroes patrios. De acuerdo con la nota publicada por la Revista Semana, "A los museos nacionales no les gustan los conflictos" (2012, 3 de marzo), la artista Beatriz González, quien fue directora del museo durante más de diez años, afirmó que la labor de las directivas del museo no debería haber sido llenar el espacio de gente ni generar impacto mediático sino proteger y conservar la memoria del país. Las pelucas - para ella - no tenían lugar en una exposición como esa. Mientras que, de acuerdo a su curadora, Cristina Lleras: "Lo que se pretendía era simplemente señalar que en nuestras historias nacionales no tenemos una presencia fuerte de héroes o personajes insignes afrocolombianos, a pesar de que los esclavos y los mulatos también hicieron la Independencia”. La inclusión de nuevas voces en las narrativas sobre la nación y los medios elegidos para que se expresen han sido foco de debates públicos donde tanto los funcionarios como los especialistas y el público en general han participado de distintos 
modos, ya sea por medio de la prensa, blogs, cartas, textos académicos, 0 , incluso, la intervención de los espacios conmemorativos a través de grafitis.

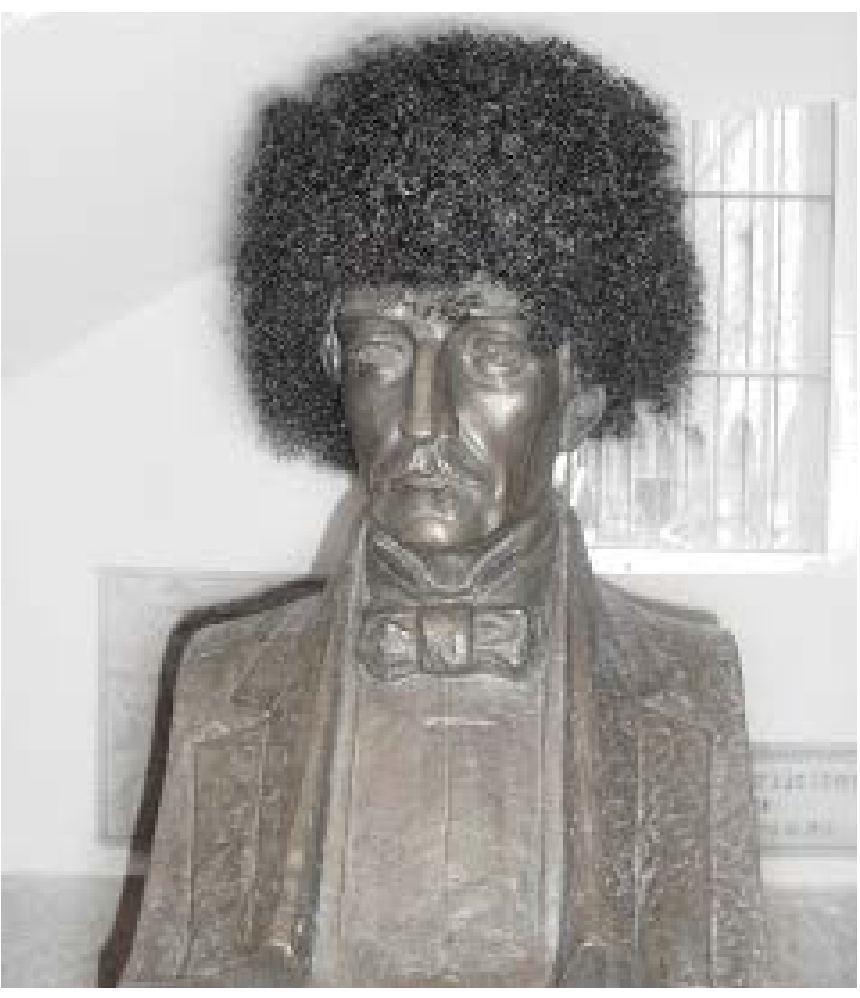

Figura 3. Fotografía: Intervención de estatuas de la colección permanente del MNC (Fory, 2012).

Más recientemente, se han podido observar estos dilemas sobre cómo pensar a la nación en las reflexiones derivadas a partir de la inauguración de la muestra Memoria y Nación, abierta al público desde el 11 de diciembre de 2014, la cual ha sido presentada como una base experimental para la futura renovación del guion general del MNC. Esta renovación ha sido pensada del siguiente modo: el primer piso titulado “Territorio”, tendrá como objetivo mostrar representaciones que integren las características físicas del espacio y las manifestaciones socioculturales allí generadas como resultado de procesos de adaptación. El territorio se abordará desde tres temáticas: pensar y conocer el territorio, habitar el territorio y moverse por el territorio. El segundo piso titulado "Recursos naturales. Procesos sociales y políticos de la nación” buscará presentar históricamente a las comunidades, al igual que sus formas de organización social, política y cultural que dan sentido a la nación. Se problematizará la apropiación del territorio, el ser político de los individuos y las sociedades, así como las tensiones y conflictos presentes en la historia de la nación. El tercer y último piso se titula "Espiritualidad y religiosidades. Lenguajes de creación”, allí se pretende representar una actividad inherente al ser humano que es la producción de imágenes a través de diferentes prácticas, oficios y técnicas que han permitido la posibilidad de trascender y permanecer, más allá de motivaciones religiosas, sociales, políticas o puramente estéticas.

Con base en esta subdivisión, el propio edificio del museo es resignificado como un universo simbólico que articula lo terrenal con lo cosmogónico, lo particular con lo universal a través de la muestra de las apropiaciones culturales de la naturaleza y las distintas formas de organización social.

\section{Memoria y Nación: las potencialidades y limitaciones de lo unívoco/plurívoco, lo explicito/implícito, la explicación/ comprensión para narrar la nación}

Tal como indica Fernando López Barbosa (2001, p. 29-39), de acuerdo con la definición de museo del Consejo Internacional de Museos (ICOM), éste debería cumplir con cinco actividades básicas: investigar, adquirir (coleccionar), conservar, comunicar y exhibir, funciones cuya ejecución debe estar orientada específicamente a cumplir con tres propósitos: estudio, educación y deleite, por ser el museo una institución al servicio de la sociedad y de su desarrollo. Pero, justamente el componente que remite al placer se ve entredicho cuando el museo se plantea no sólo deleitar sino incomodar a través de la disrupción del sentido común de lo que se ha sobreentendido como lo nacional, lo patrio o lo honorable. 
La tensión que genera repensar la nación para construir un relato apropiable por parte de una población cultural e ideológicamente heterogénea se puede observar en la creación de la sala Memoria y Nación del MNC donde se exhibe una acumulación de objetos que remiten a momentos históricos controversiales del país y a conflictos políticos y culturales que siguen vigentes. La sala Memoria y Nación exhibe una sección que agrupa el bastón de un palabrero wayúu, hecho en bejuco, junto con un lingote en acero, hecho con las armas enfundadas por el M-19 y la estilográfica con la que se firmó la Constitución de 1991. Lo anterior, según la ex directora del Museo María Victoria Angulo de Robayo, "corresponde a un deseo por mostrar un momento histórico - como lo fue la adopción de esta nueva carta magna - junto a objetos que representan el fin del grupo guerrillero y que, como el bastón, permiten que el público pueda hacer una lectura de cómo se resuelven los conflictos en Colombia” (Toro Vesga, 2014) en un contexto político donde se están llevando adelante negociaciones de paz entre el gobierno y la guerrilla de las FARC. Como explica el curador Jaime Cerón, quien participó en la creación de la nueva línea narrativa "La idea [...] es que el Museo Nacional encarne el pluralismo del que habla la Constitución del 91” "¿LLos museos deben reinventarse?”, 2015) ${ }^{5}$.

Otra sección de la misma sala ofrece el muro de la diversidad donde conviven pinturas como "La mulata cartagenera”, de Enrique Grau, "La raza en la calle”, de Débora Arango, o retratos como el de Dimas Daza, "El último soldado de Nariño" junto a rostros anónimos, paisajes de Boquerón, del Río Apulo, y representaciones humanas hechas por los muiscas que datan del siglo XVII. Por otro lado se reúnen diferentes aproximaciones a la naturaleza, a partir de piezas como "El árbol de la abundancia", de Abel Rodríguez, o, el atril que perteneció a José Celestino Mutis y sobre el cual se realizan unas proyecciones que asemejan el movimiento de las hojas de un libro. Este es tan solo uno de los elementos multimedia que hacen, según los curadores, más dinámica y accesible la información que se despliega para un público heterogéneo. Por tal motivo, cada texto que acompaña a los objetos se encuentra en inglés, en castellano y en sistema Braille junto a una versión en audio.

En otra parte de la sala también se ve cómo el arte ha abordado la violencia, con obras como "David n. ${ }^{\circ}$ ", de Miguel Á. Rojas, "San Sebastián en las trincheras”, de Ignacio Gómez J., y otras de Carlos Granada y Umberto Giangrandi, acompañado de los telares de Mampuján junto a un audio en que hablan las mujeres que lo elaboraron, víctimas del desplazamiento forzado ocasionado por paramilitares del bloque "Héroes de Montes de María” en el 2000.
5En la Constitución de 1991 Colombia fue definido como "un Estado social de derecho, organizado en forma de República unitaria, descentralizada, con autonomía de sus entidades territoriales, democrática, participativa y pluralista, fundada en el respeto de la dignidad humana, en el trabajo y la solidaridad de las personas que la integran y en la prevalencia del interés general" (Artículo 1). 


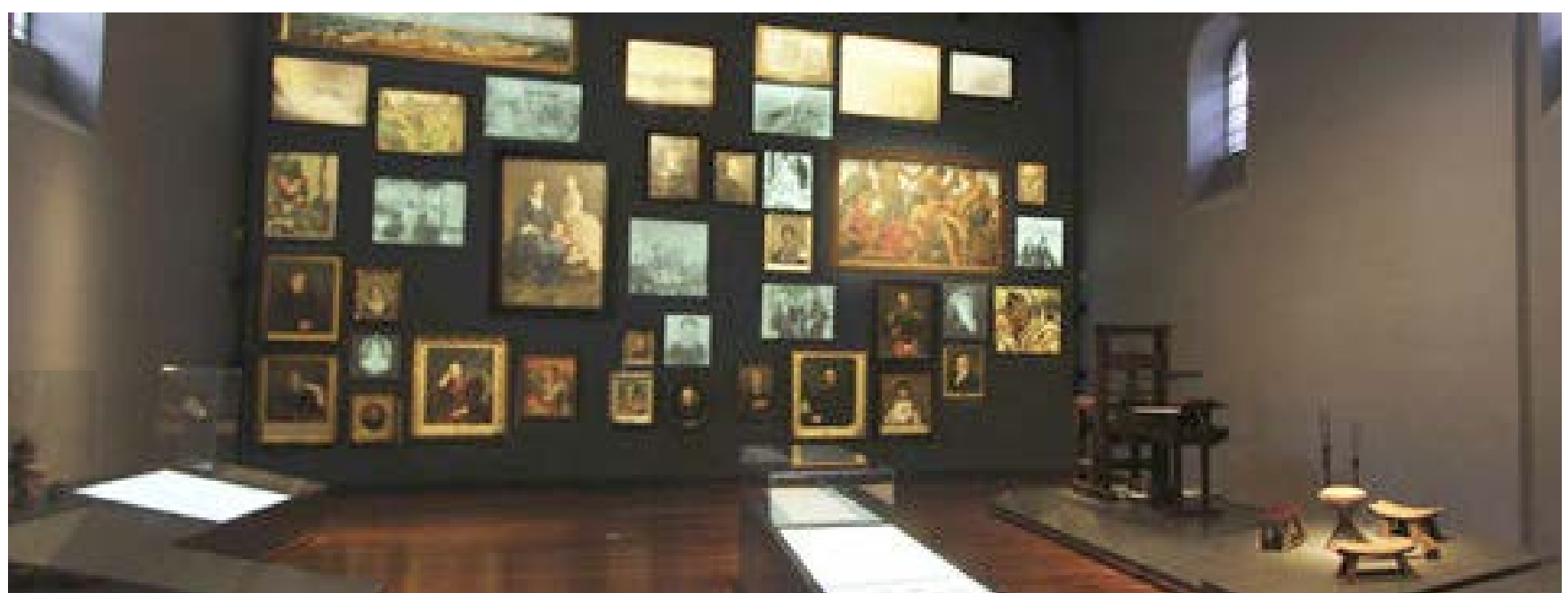

Figura 4. Pinturas y videos expuestos en el muro de la diversidad, parte de la muestra Memoria y Nación, MNC (EFE, 2014).

Desde el simposio “Museo, memoria y nación”, que tuvo lugar en 1999, surgió la necesidad de replantear la narrativa de la historia que presenta el MNC con el fin de mostrar la diversidad étnica y cultural del país (Sánchez y Wills, 2000). Con base en esta necesidad, para los organizadores de la muestra Memoria y Nación, con ella se busca que los visitantes conozcan la historia de Colombia a través de múltiples lecturas incluyendo el relato de personajes y procesos que no habían sido visibles hasta ahora. La sala es definida del siguiente modo:

Un espacio conceptual que aborda temas como las fusiones en el mundo de lo sagrado, la oralidad y la escritura en la construcción y transmisión del conocimiento y la memoria, entre otros contenidos.

El elemento central de la exhibición será el 'Muro de la diversidad', donde se resume el ejercicio de inclusión sobre el que se construye la nueva narrativa del Museo Nacional. Además, en cada sección de la sala los visitantes encontrarán piezas emblemáticas de las cuatro colecciones del Museo [arte, historia, arqueología y etnografía] con un montaje contemporáneo a través de herramientas multimedia de última tecnología (“El Museo Nacional abre su sala 'Memoria y nación”, 2014).

Esta muestra discute con la construcción de un relato único donde la autoridad reside en quien enuncia: el curador de la exposición. Los objetos de distintas épocas, clasificados por su significación socio-histórica y cultural en vez de por su pertenencia a distintas capas geológicas de una cronología nacional única, buscan movilizar sensaciones por parte del espectador, con el fin de comunicar una forma de mirar a la nación o a lo nacional que genere cuestionamientos sobre la configuración ciudadana y del Estado colombiano. A partir de objetos evocadores que permiten rememorar hechos sensibles para la población, se procura arrimar distintas dimensiones temporales entre sí — pasado, presente y futuro—con la intención de promover la reflexión sobre el peso de la historia en el presente y cómo el presente también moldea el pasado. Es por ello que, en términos historiográficos, el guion no resulta lineal y es disrupti- 
vo con relación al resto del museo, que se sustenta en una idea museológica clásica ligada a una idea de Nación vinculada a sus orígenes prehispánicos, republicanos y la conformación de las élites gobernantes. La muestra, de este modo, presenta una serie de pliegues de memoria en el curso de un relato histórico que se abre a controversias y a ser reconstruido por el propio visitante en tanto intérprete de símbolos polisémicos, yuxtapuestos en un espacio compartido a pesar de no ser necesariamente exponentes de los mismos períodos históricos.

Más allá de las fundamentaciones de los curadores y directores de la muestra, si bien este tipo de aproximación museográfica procura conjurar la mirada positivista, pretendidamente objetiva de la historia, no necesariamente restituye las voces a sus enunciadores, sino que coloca la responsabilidad y el peso de la interpretación histórica en el público visitante. Es decir, se abstrae de plantear un punto de vista imparcial pero tal vez no deja de plantear un punto de vista ideal, el de la relatividad cultural y el humanismo universal. Para Foucault (1992, p. 18-19) toda historia será siempre la manifestación de una perspectiva que pretende alzarse con la totalidad y la neutralidad, pero no sabe que su intervención misma en la guerra por los sentidos y las verdades evidencia su posición y, entonces, su parcialidad.

La muestra Memoria y Nación pareciera justamente tomar una posición crítica respecto a la forma en que fue pensada y narrada la historia nacional colombiana pero, al mismo tiempo, esta posición no centrada en un relato único y lineal pareciera operar también como una forma de evasión que se desliga de la responsabilidad que le ocupa en cuanto al lugar de poder que es el propio Museo Nacional como dispositivo cultural estatal. Por otro lado, si nos situamos en el plano de la recepción, se abren una serie de cuestionamientos sobre la comprensión de esta multiplicidad y yuxtaposición de objetos sin un relato articulado. Como se pregunta el periodista Nicolás Morales (2015): ¿se trata de un museo plural pero incomprensible?

Me encontré con un espacio hecho de fragmentos, rostros e imágenes deshilvanadas. Digo yo: nombrar al otro no es necesariamente incluirlo. El sincretismo como fenómeno no es un evento meramente estético como lo sugiere esta sala. Se debería visibilizar la potencia creadora del encuentro entre tradiciones diversas para contarnos como nación. Las presencia de las frutas americanas en un altar barroco o el uso de unas plumas nativas en un tapete colonial no me explica nada. Parece un collage básico. El contraste entre la oralidad y la escritura me pareció muy simple al abordar el tema de la construcción y transmisión del conocimiento desde una mirada diversa. ¿Dónde quedan los manifiestos políticos (escritos) de Quintín Lame ${ }^{6}$ ? ¿Dónde queda el uso estratégico de los títulos coloniales que han hecho los indígenas para reivindicar sus derechos? Si queremos lanzarnos al arduo trabajo de pensar una nueva narrativa de nación, tenemos que empezar por abandonar los estereotipos que hemos construido alrededor de la diferencia.

Esta apreciación sobre la ausencia de un guion articulador de un relato sobre lo nacional, también ha quedado expresada en la editorial de la revista Arcadia (Editorial 116, 2015):

Sobre la nueva sala Memoria y Nación, unos dicen que tiene muchas virtudes, pero se quedó como un prólogo de un museo que no existe. Quien vaya, además, se hará preguntas de fondo, como dónde están representados los gais, por solo nombrar una de las minorías pasadas por alto en la curaduría.

6 El Movimiento Armado Quintín Lame (MAQL) fue una guerrilla indígena colombiana activa desde 1984 hasta su desmovilización en 1991. Fundamentalmente operaba en el departamento del Cauca, sur-occidente colombiano. 
Ana Guglielmucci

Esta propuesta de transformación del guion del MNC y lo que ello plantea en términos de relato sobre la nación y la autoridad museográfica, ha sido objeto de debate no sólo por las reacciones que promueven un relato tradicional sobre el Estado-Nación sino también por otros sectores críticos que indican las limitaciones de un guion plurívoco y fragmentado para un público no habituado a visitar museos, donde actualmente predomina la aproximación del arte conceptual por sobre la comunicación y recepción de información de un modo explícito, organizado y direccional. Desde ciertos puntos de vista, pareciera que el guion supone que la sola yuxtaposición de objetos puede comunicar la incoherencia de un discurso tradicionalmente legitimado o los vacíos omitidos en la comunicación: lo no dicho sobre la configuración nacional. Tal como formuló el artista Fred Wilson en 1992 en Estados Unidos cuando propuso la exposición "Mining the Museum” que presentó la colección de Maryland Historical Societybajo una nueva perspectiva crítica: "What they put on view says a lot about a museum, but what they don't put on view says even more" ["Lo que se pone a la vista dice mucho sobre un museo, pero lo que no se pone dice aún más”. Traducción de la autora]7. Como si los objetos no necesitaran explicación alguna, pues la yuxtaposición de elementos, en un principio incoherentes entre sí, lo dice todo de un modo satírico o irónico universalmente comprensible. Con

7 Maryland Historical Society fue creada en 1844 para coleccionar, preservar y estudiar objetos relacionados con la historia del estado. Su misión incluyó cuestiones como la colonización, la esclavitud y su abolición, pero el museo tendió a presentar esta historia desde el punto de vista de sus financiadores. Esta perspectiva es lo que Wilson trató de minar. Para ello expuso las colecciones del museo de una manera novedosa, desarrollado técnicas satíricas e irónicas para criticar al propio museo desde adentro. Por ejemplo, expuso un juego de té hecho de plata junto a unas esposas de hierro para mostrar que el metal sirvió para lucirse y para esclavizar, que el material con el cual los grupos gobernantes demostraban su superioridad había sido extraído por las personas esclavizadas. De acuerdo a los críticos, "Mining the Museum” fue efectivo porque fue sugestivo más que didáctico, provocativo más que moralizante. Véase Beautiful Trubel. A tool box for revolution. Case Study: Mining the museum. Recuperado de http://beautifultrouble.org/case/mining-themuseum/ esto no se quiere negar el poder de los vacíos y de lo disruptivo para abrir nuevas preguntas sobre lo dado o evitar la clausura de la interpretación, tal como ya lo ha señalado Nelly Richard en su obra "Fracturas de la memoria. Arte y pensamiento crítico" (2007) pero, al mismo tiempo, se abre la interrogación sobre los efectos de la fragmentación y la irrupción en la recepción de mensajes y las posibilidades de decodificación por parte de un público heterogéneo con distintos bagajes sociales, culturales, ideológicos. En definitiva, se plantea cuál es la posibilidad de transmitir un mensaje plurívoco sin caer en un relativismo extremo que roce lo superficial o privativo, y cuál es la distancia óptima que media entre la explicación, la comprensión y la revisión de fenómenos históricos complejos como el (des)encuentro entre tradiciones culturales con poderes políticos-económicos diversos.

Algunos de estos debates sobre cómo representar a la nación y los conflictos vinculados a su configuración política, cultural y económica también pueden rastrearse en el proceso de creación del Museo Nacional de Memoria Histórica.

\section{El Museo Nacional de Memoria Histórica}

La idea del Museo Nacional de la Memoria en Colombia se puede pensar como el resultado de un largo proceso social que ha durado varias décadas, en el cual el país se ha confrontado a la imposibilidad de invisibilizar hechos dramáticos que han causado grandes sufrimientos sociales a una gran parte de la población, de marginar las narraciones de aquellos que no tenían posibilidad de ser escuchados y, finalmente, debido a las presiones políticas internas y externas que han buscado zanjar el conflicto y que el Estado asuma su responsabilidad de cara a las víctimas ${ }^{8}$.

8 El Decreto 4803 del 20 de diciembre de 2011 reglamentó la Ley 1448 del 10 de junio de 2011, más conocida como la ley de víctimas, la cual otorgó al CNMH la función de "Diseñar, crear y administrar un Museo de la Memoria, destinado a lograr el fortalecimiento de la memoria colectiva acerca de 
En estos últimos años, con marchas y contramarchas y una agenda de debates poco despejada, el CNMH ha avanzado en la definición del contenido del proyecto para crear un MNMH a través de la organización de algunas actividades restringidas a ciertos actores como servidores públicos, especialistas y colectivos de víctimas, y otros encuentros más o menos abiertos al público en general. A través de tales eventos se ha empezado a delimitar la forma, ubicación, gestión y contenido del futuro museo.

Si bien el MNMH es concebido como "un avance determinante en el deber de memoria del Estado que redunda en la garantía del derecho correlativo de la sociedad colombiana en su conjunto a la construcción permanente de la

los hechos desarrollados en la historia reciente de la violencia en Colombia, procurando conjugar esfuerzos del sector privado, la sociedad civil, la cooperación internacional y el Estado”. Este Museo, según la Ley, “deberá realizar las acciones tendientes a restablecer la dignidad de las víctimas y difundir la verdad sobre lo sucedido". Asimismo, el Museo deberá atender el mandato normativo relacionado con memoria histórica y comunidades étnicas contemplado en tres decretos con fuerza de ley (4633, 4634 y 4635 de 2011) para los pueblos indígenas, comunidades negras, afrodescendientes, raizales y palenqueras y comunidades Rom. Esta serie de decretos, en la medida en que se inspiran en conquistas de las organizaciones sociales y étnicas en materia de adecuación institucional a la diversidad cultural del país, señalan una ruta de trabajo que es necesario articular a la concepción del Museo, en la perspectiva de consolidar un ejercicio verdaderamente intercultural en la realización del derecho y el deber de la memoria histórica. memoria y la paz" (Concurso público de anteproyecto arquitectónico para el diseño del Manseo Nacional de la Memoria, 2015, p.17); y es pensado como una de las principales "medidas de reparación y de satisfacción para las víctimas del conflicto armado en Colombia” ( $p$. 17) es importante destacar que para las propias organizaciones de víctimas, por un lado, ya la sola ubicación en la ciudad de Bogotá resulta problemática, pues el conflicto ha tenido lugar principalmente en la zonas rurales, y por otro lado, también les resulta dudoso su carácter reparador en un país donde gran parte de la población continúa en una situación cotidiana de conflicto armado y profunda inequidad social.

La propuesta de crear un MNMH sobre el conflicto armado ha generado diversidad de opiniones en las que se destaca la necesidad de generar espacios que incluyan, sobre todo, los requerimientos de las comunidades afectadas. Para algunos actores involucrados en el proceso de creación del MNMH, como la curadora Cristina Lleras, ha habido varias diferencias en cómo debería encararse el trabajo, mientras que algunos funcionarios y especialistas han considerado que debía erigirse un monumento de gran tamaño, otros han pensado que antes de encargar a un artista una obra monumental en Bogotá, donde ya existe el Centro de Memoria Paz y Reconciliación (CMPyR) administrado por el Distrito, sería necesario pensar en las necesidades materiales y de seguridad de los afectados y si, en realidad, la sociedad nacional se apropiará de una propuesta cuya finalidad es sanar un duelo colectivo de larga data. En palabras de Lleras, algunos de los principales desafíos vinculados a la creación de un MNMH son: ¿cómo generar un proceso en el que se reconozcan las responsabilidades no sólo de los propios victimarios, sino de los que se lucraron con el conflicto e incluso de los culpables por omisión o encubrimiento de los hechos delictivos? (Lleras Figueroa, 2008). O, ¿cómo hacer visibles los procesos en que se reconoce el daño pasado, sin abolir la posibilidad de generar acciones presentes y proyectos hacia el futuro por parte de las comunidades afectadas, es decir, sin revictimizarlas? De acuerdo con la curadora, "el reto es lograr que estas reflexiones tengan impacto en el conjunto de la sociedad, que sea claro que si bien miles son víctimas, otros miles también tenemos una responsabilidad colectiva". Pues, como ya ha sido destacado por numerosos estudiosos y especialistas (Yersushalmi et al., 1998), la verdad no garantiza la no repetición de los hechos, ni es suficiente saber la verdad o reconocer el daño individual y colectivo para cambiar el curso de la historia si esto no genera una reflexión de la sociedad en su conjunto. Más allá de estas observaciones especializadas en torno al proyecto del MNMH y otras discusiones sostenidas en unos pocos debates 
Ana Guglielmucci

públicos como el realizado en 2014 en Bogotá; de acuerdo con lo estipulado en la Ley de víctimas, el 9 de abril de 2015 se realizó un acto simbólico para anunciar la ubicación del futuro museo en la ciudad de Bogotá, muy cerca del CMPyR, sobre la Calle 26 (Avenida el Dorado), una ruta troncal de la ciudad en la que se articularán distintos sitios conmemorativos o de memoria en un Eje de la Paz y de la Memoria ${ }^{9}$. En el marco de la celebración del Día Nacional de la Memoria y Solidaridad con las Víctimas del Conflicto Armado, el presidente Juan Manuel Santos en compañía del alcalde de Bogotá, Gustavo Petro, llevaron a cabo un acto simbólico en el cual se encendió una llama de esperanza en el lugar donde se edificará el museo. En dicha actividad, sólo hablaron los representantes del gobierno nacional y distrital, aunque una representante de una organización de derechos humanos local logró hacerse en el escenario para plantear el punto de vista de su organización compartido por varios colectivos de víctimas. El mensaje fue que no los dejaran por fuera de las discusiones y que el Museo debía ser un lugar vivo donde lo que está pasando en otras regiones y localidades fuera incluido en el relato general sin ser subsumido por una mirada hegemonizada por la administración gubernamental. En este acto oficial las organizaciones de víctimas, a pesar de lo que afirma la Ley, no tuvieron un lugar central en el escenario y su voz debió hacerse sentir a la fuerza.

Posterior a este acto simbólico en el lugar donde se ubicará el futuro MNMH, el CNMH elaboró y publicó las bases para la realización de un concurso arquitectónico internacional dirigido a establecer el diseño del museo que tiene como finalidad mostrar las huellas de la violencia a lo largo del país, reco-

9 La ruta que va desde el camino a Monserrate a la Plaza de la Democracia y al lugar escogido para la construcción del Museo Nacional de Memoria Histórica, en la Calle 26 JEG con Avenida 30, ha sido reconocida como el Eje de la Paz y la Memoria con el decreto distrital 632 de diciembre de 2014. Camilo González Posso (2015) “Eje De La Paz y La Memoria. La Reconciliación en Símbolos Urbanos de Memoria y Paz”. Recuperado de https:// centromemoriabogota.wordpress.com/eje-de-la-paz-y-lamemoria/ nocer la pluralidad de las víctimas del conflicto, la representación de la violencia que han sufrido sus regiones y los habitantes de las mismas ${ }^{10}$. El ganador del concurso ha sido la dupla integrada por las oficinas MGP Arquitectura y Urbanismo (Colombia) y estudio.entresitio (España) que se adjudicó el primer lugar entre las 72 propuestas participantes del concurso público. Apelando "al rescate de la memoria como antídoto efectivo frente a la negación, la deformación o la indolencia frente a la violencia” (Valencia, 2015), en las propuestas presentadas el concurso buscó la conceptualización del edificio como un "homenaje profundo y conmovedor a las víctimas” del conflicto armado colombiano que al mismo tiempo "celebra la esperanza del próximo futuro".

La concepción que subyace a la iniciativa del Museo es que la historia del conflicto armado debe contarse necesariamente desde la perspectiva de las víctimas de una manera plural y flexible; sin embargo, es muy poco lo que se ha hablado del papel que deben jugar los protagonistas de la guerra en todo este proceso, especialmente, guerrilleros, paramilitares y FFMM, además de las organizaciones de víctimas. A su vez, poco se ha hablado de cómo será su gestión o forma de administración y la definición de los contenidos de modo tal que incorporen la diversidad cultural y la variabilidad histórico-regional del conflicto armado y sus impactos materiales y simbólicos para la población nacional. De acuerdo a sus gestores, el MNMH contará con cinco ejes centrales: "Qué pasó en estos 50 años de conflicto; por qué ha pasado lo que ha pasado; los daños e impactos a las víctimas; la resistencia, la dignidad y la

10 El Concurso Arquitectónico buscó la mejor propuesta que lograra articular espacialmente un programa arquitectónico de por sí complejo con un conjunto urbanístico de especiales características. También, requirió que el diseño fuera emotivo, plural, estético, flexible y simbólico. Teniendo en cuenta estas particularidades, la Sociedad Colombiana de Arquitectos, el Centro Nacional de Memoria Histórica y la Alcaldía Mayor de Bogotá seleccionaron a cinco profesionales para escoger la firma ganadora que diseñará el futuro Museo Nacional de la Memoria. Las bases del concurso pueden consultarse en http:// centrodememoriahistorica.gov.co/museo/museo/construccionmaterial. 
paz y; por último, nuestro presente, las otras violencias y los retos que nos presenta” "Colombia contará con Museo Nacional de la Memoria”, 2015). Pero los colectivos de víctimas, no han sido parte integral del jurado ni de las discusiones centrales, no sólo en torno a la forma, sino al financiamiento y a la gestión del Museo. Esto es muy diferente a cómo ha sido el proceso de creación de espacios para la memoria sobre el terrorismo de Estado en la Argentina, donde los organismos de derechos humanos integrados por afectados directos han tenido un rol central en estos temas, al menos en un principio, incluso, formando parte de los jurados y comisiones donde se tomaban las decisiones sobre qué hacer en cada lugar (Guglielmucci, 2013, p. 239).

Si bien la ubicación y la forma arquitectónica del Museo han sido definidas, aún no se ha precisado y socializado cómo será la administración del museo, sus contenidos y formas de transmisión, sus colecciones y modalidades de exhibición, los discursos y narrativas que lo constituirán. Algunos actores están preocupados por el lugar que tendrán sus propias formas de representación de los hechos victimizantes y sus proyectos y necesidades actuales para el desarrollo de su vida cotidiana. Por ejemplo, un problema central para las comunidades afrocolombianas que no han podido enterrar a sus muertos es que ello no sólo afecta a las personas sino que rompe lazos de solidaridad que se activan y renuevan en los rituales mortuorios. Estos eventos comprenden una rica dimensión simbólica, amenazada por los asesinatos, desapariciones y desplazamientos forzados a los que se ven sometidos. ¿De qué manera este tipo de problemas van a ser evocados en el Museo? ¿Cómo se lograrán construir símbolos flexibles, plurales y emotivos que incluyan a toda la población colombiana y al mismo tiempo no desdibujen las diferencias culturales e históricas internas? Si bien se propone que esto puede resolverse a través de la creación de iniciativas y espacios conmemorativos a nivel local, ello no elude el desafío de establecer símbolos comunes que permitan generar una base de consenso para entender el pasado-presente y emprender cambios comportamentales e ideológicos a futuro con miras a la reparación y reconciliación nacional.

Este tipo de problemas locales, vistos como particulares, revelan la complejidad de la esfera simbólica que no puede limitarse a lo que genere la verdad judicial ni una forma de reparación que no contemple la diversidad étnica, cultural y religiosa que tiene el país, que combina la centralización político-administrativa con la fragmentación regional del poder. A su vez, a ello se suma que los procesos de victimización han sido diversos histórica y regionalmente. Incluso, los grupos armados sindicados como victimarios en un momento, pueden ocupar el lugar de víctimas en otro. En este sentido, el museo puede jugar un rol central en la divulgación de formas culturales de representar el conflicto en su escenario local o puede ocluir formas locales de lidiar con una serie de conflictos regionales de larga data que aún se están desarrollando y que son funcionales a dinámicas económicas de grupos hegemónicos. De hecho, paradójicamente, la actual locomotora del desarrollo tiende a nutrir conflictos sociales al mismo tiempo que se imponen procesos de memoria histórica sobre eventos críticos determinados.

El museo puede explorar los diferentes matices del conflicto y de la violencia en contextos geográficos e históricos heterogéneos pero, ello puede atentar para la consolidación de una comprensión integral de las causas y consecuencias de estos hechos. Puede develar las causas de las transformaciones, rupturas y continuidades del conflicto armado y sus consecuencias, pero ello puede no encontrar eco en la perspectiva de amplios sectores de la población que más allá de estas explicaciones pueden ceñirse a lo estrictamente experiencial en su ámbito de vida donde tal vez los grupos armados hayan sido vistos como "salvadores" o como "restauradores del orden" frente a otros grupos armados o de cara a la corrupción 
Ana Guglielmucci

por parte de las autoridades gubernamentales locales o regionales. Es decir, en una situación donde un grupo armado al dominar una zona se impuso por años con cierta legitimidad, puede contar con el apoyo de la población aunque ella no lo reconozca abiertamente o no salga a disputar el relato del MNMH.

En este contexto, ¿cómo explicar las masacres, los secuestros extorsivos, el desplazamiento y las desapariciones forzadas?, ¿cuál es la posibilidad de comprenderlo y lograr evitarlo en un futuro?, ¿por qué hacerlo desde la perspectiva de las víctimas y cuáles son las limitaciones que se plantean? $\mathrm{Mu}-$ chas son las preguntas y aún pocas son las respuestas que se han generado en torno al contenido del MNMH.

\section{Los museos de la memoria}

La creación de un MNMH en Colombia ha generado ya varios debates antes de su construcción, aunque la mayoría de ellos se han dado a puertas cerradas. Por un lado, se han desarrollado opiniones encontradas en cuanto a la manera de narrar la dura realidad de un conflicto armado que lleva más de cincuenta años, se ha cuestionado su ubicación en la ciudad de Bogotá dado que su epicentro ha tenido lugar en las zonas rurales más que en las zonas urbanas y, por otro lado, se han realizado ciertos cuestionamientos por la partida presupuestaria que costará su edificación, calculada en unos 44 mil millones de pesos.

Entre los actores que se han manifestado públicamente frente a la iniciativa del MNMH, las Fuerzas Armadas de Colombia ya han expresado públicamente su preocupación por la manera en que este museo narrará las causas y consecuencias del conflicto armado interno. Especialmente los agita la forma en que se explicará el rol del Ejército en la retoma del Palacio de Justicia (1985) o las ejecuciones extrajudiciales de jóvenes de bajos recursos hechos pasar por guerrilleros, caso conocido en la prensa como los "falsos positivos", hechos por los cuales han sido procesados varios altos mandos de las FFMM por crímenes de lesa humanidad.Dada esta preocupación, junto al programa del MNMH coexiste otro proyecto para narrar el conflicto armado: el Parque Museo de las Fuerzas Militares de Colombia. La iniciativa de las FFMM se trata de un megaproyecto que se está erigiendo en un terreno de 11 hectáreas en Tocancipá, próximo a Bogotá, y cuyo costo supera los 20 mil millones de pesos, la mayoría de los cuales provienen de donaciones privadas. En palabras de su director, el general Luis Gómez: "se trata de un lugar que 'se convertirá en el centro de memoria histórica por excelencia de nuestro país" " (Montaño, 2015). De acuerdo a este general, el objetivo del Parque Museo es ampliar la mirada de que la memoria histórica sólo tiene que ver con el conflicto armado y "mostrar que ese concepto también incluye a las batallas de La Independencia y la importancia de las Fuerzas Militares en los 200 años de vida republicana”. Para el general Vásquez, director del Centro de Memoria Histórica de la Escuela Superior de Guerra, uno de los objetivos del Parque Museo es contrarrestar las malas críticas a las FFMM y reivindicar su conducta durante el conflicto, más allá de las denuncias y procesamientos de varios altos mandos del Ejército:

'Este museo es fundamental para la sostenibilidad de la fuerza, aquí la gente no es consciente de lo que han hecho los soldados por el país y esa es una de las razones por las que se tergiversa la historia', y pone como ejemplo los falsos positivos: 'Cuando es un grupo ínfimo que no llega ni al 0,2 por ciento del total de las Fuerzas Militares' (Montaño, 2015).

Para otros actores, más que ampliar la mirada, el proyecto del Parque Museo es una forma de hacer propaganda sobre las FFMM de Colombia cuando varios de sus integrantes están siendo procesados por crímenes de lesa humanidad. Por ejemplo, la abogada Yessika Hoyos, integrante del Colectivo de 
abogados José Alvear Restrepo, afirma que en un museo de este tipo:

Debería hablarse de las consecuencias de las políticas de seguridad nacional y de la doctrina del enemigo interno sobre las organizaciones sociales y de izquierda. 'Eso explicaría cómo, con la excusa de la lucha contrainsurgente, se frustraron muchos proyectos legítimos para construir un país diferente' (Montaño, 2015).

La principal diferencia que reconocen los promotores del MNMH respecto al Parque de las FFMM es, por un lado, que la memoria debe ser crítica y no puede ser una oda que exalte únicamente las virtudes de quienes la elaboran y promueven. Según la perspectiva de la directora del MNMH, Martha Nubia Bello, la memoria tiene que interrogar y, en últimas, debe servir para aprender de lo que se hizo mal. Y, por otro lado, la narrativa de esta iniciativa nacional debe centrarse en la reconstrucción de la historia del conflicto armado a partir de las voces de las víctimas y no de los combatientes. Esta premisa, tal vez, sea una de las representaciones museísticas que genera más debate, puesto que la guerra colombiana ha sido larga y de una degradación tal, que es difícil marcar las fronteras entre víctimas y victimarios. En las propias palabras de Bello: "He conocido relatos de víctimas de desplazamiento que no han tenido otra opción que vincularse a los paramilitares. ¿A estas personas en qué lugar las colocas?” (Montaño, 2015). Definitivamente la guerra en Colombia difícilmente pueda calificarse en términos de blanco y negro.

El Parque Museo de las FFMM, al ser un intento de legitimación de un actor que ha puesto una importante cuota de víctimas, entra en abierta contradicción con la política impulsada desde el MNMH. Si bien reconoce que ha afectado a la población civil, al diluir la magnitud de su responsabilidad, impide la reparación integral, porque niega a muchas de sus víctimas y con ello obstaculiza uno de los fines principales de la memoria: el esclarecimiento definitivo de lo que ha pasado en la guerra, una guerra que, por otro lado, aún continúa. Pero quizá el fin de la memoria no sea únicamente el esclarecimiento, sino también la posibilidad de volver un pasado inteligible de un modo y no de otro.

La memoria histórica es hoy un campo de disputa entre versiones del pasado reciente, encarnadas por diferentes actores, como los múltiples colectivos de víctimas existentes, servidores públicos, y los propios grupos armados, al margen de la ley o no. Cómo se cuente la historia de este largo conflicto tendrá repercusiones en muchos aspectos de la vida de las personas, desde cómo se definan las responsabilidades jurídicas y morales, las indemnizaciones administrativas, el presupuesto asignado a las agencias estatales, entre muchas otras. Por eso mismo, el tratamiento del conflicto y la creación de un MNMH es una esfera de actividad que cada vez involucra a más personas pero en la que no todos tienen la misma capacidad de imponer sus representaciones sobre los otros. En este punto, las instituciones públicas como el MHNC y el MNMH juegan un rol central, pues cuentan con un capital económico, cultural y simbólico importante, que puede tener un impacto directo sobre lo que se construye, narra y muestra como memoria común pensada en términos nacionales. Por ello mismo, el análisis de la memoria como fenómeno social y sus formas de representación museística implica pensar la memoria como un campo de debates y luchas sobre verdades, pero también sobre legitimidades políticas para hablar públicamente del pasado-presente traumático con vista a un futuro político incierto. De allí que las formas en que las nuevas directivas del MHN y del CNMH articulen el trabajo para la renovación del MHN y la construcción del MNMH será definitorio a la hora de delimitar sus contenidos y la recepción de los mismos, pues, como se dice en el lenguaje museológico, el continente y el contenido difícilmente pueden pensarse como dos realidades escindidas. 


\section{Referencias}

A los museos nacionales no les gustan los conflictos (2012, 3 de marzo) Semana. Recuperado de http://www.semana.com/ cultura/articulo/a-museos-nacionales-nogustan-conflictos/254324-3

Allier Montaño, E. (2008). Los Lieux de mémoire: una propuesta historiográfica para el análisis de la memoria. Historia y Grafía, núm. 31. 165-192.

Angulo de Robayo, M. V. (2014, 3 de septiembre). "Repensar el museo. El Museo Nacional abre la primera sala transformada con el nombre de Memoria y nación”. El Tiempo, Colombia. Recuperado de http://www. eltiempo.com/lecturas-dominicales/lecturasdominicales/14481148

Benjamin, W. (1973). Discursos interrumpidos, I. Madrid: Taurus.

Colombia contará con Museo Nacional de la Memoria (2015, 7 de abril) El Colombiano. Recuperado de http://www.elcolombiano. com/colombia-contara-con-museo-nacionalde-la-memoria-FB1663878

Concurso público de anteproyecto arquitectónico para el diseño del Manseo Nacional de la Memoria (2015). Recuperado de http://www. centrodememoriahistorica.gov.co/descargas/ concursoMuseos/BASES-MNM-LIBRO-2Introduccion.pdf

Editorial 116. (2015, 22 de mayo). Arcadia. Recuperado de http://www.revistaarcadia. com/opinion/editorial/articulo/la-noche-delmuseo/42558
EFE. (2014). Parte de la muestra Memoria y Nación. [Fotografía]. Recuperado de http:// www.eltiempo.com/entretenimiento/arte-yteatro/memoria-y-nacion-la-nueva-sala-delmuseo-nacional/14974082

Foucault, M. (1992). "Nietzsche, la genealogía y la historia”, en Genealogía del Poder, Madrid: Las Ediciones de la Piqueta, p. 7-29.

Fory, N. (2012) Las historias de un grito. 200 años de ser colombianos. [Fotografía] Recuperado de: http://historianuestracaballero.blogspot. com.co/

Guglielmucci, A. (2013). La consagración de la memoria. Una etnografía acerca de la institucionalización del recuerdo sobre los crímenes del terrorismo de Estado en la Argentina, Buenos Aires: Editorial Antropofagia.

Hacer la Paz en Colombia "Ya vuelvo", Carlos Pizarro (2011). Arcadia. Recuperado de http://www.revistaarcadia.com/agenda/ evento/hacer-paz-colombia-ya-vuelvo-carlospizarro/23462

Huyssen, A. (2002). En busca del futuro perdido. Cultura y memoria en tiempos de globalización, México: Fondo de Cultura económica.

Leal Guerrero, S. \& G. A. Gómez Angarita. (2013). "El Holocausto del Palacio de Justicia: nombres, versiones y desacuerdos” en: Restrepo Forero, Olga (Comp.) Ensamblando Heteroglosias, Tomo 2, Bogotá: Facultad de Ciencias Humanas, Centro de Estudios Sociales (CES) Universidad nacional de Colombia, p. 153-182. 
Lleras Figueroa, C. (2008, 21 de mayo).

"Reparación simbólica a víctimas es tarea fundamental para la preservación de la memoria histórica”. El Tiempo. Recuperado de http://www.eltiempo.com/archivo/ documento/CMS-4188105

López Barbosa, F. (2001). Museo Nacional de Colombia. Memorias de los coloquios nacionales: La arqueología, la etnografía, la historia y el arte en el Museo; desarrollo y proyección de las colecciones del Museo Nacional de Colombia. Bogotá: Ministerio de Cultura.

Montaño, E. (2015, 22 de abril). “¡Pacifista!: General, ¿su museo de la memoria incluye a las víctimas de las Fuerzas Militares?” Vice. Recuperado de http://www.vice.com/ es_co/read/general-su-museo-de-la-memoriaincluye-a-las-victimas-de-las-fuerzasmilitares

Morales, N. (2015, 22 de enero). "El nuevo (viejo) Museo Nacional”. Arcadia. Recuperado de http://www.revistaarcadia.com/impresa/ noticias/articulo/el-nuevo-viejo-museonacional/40744

El Museo Nacional abre su sala "Memoria y Nación” (2014). Recuperado de http:// www.colombiaaprende.edu.co/html/ productos/1685/w3-article-347942.html

¿Los museos deben reinventarse? (2015, 10 de enero). Semana, Recuperado de http://www. semana.com/cultura/articulo/los-museosdeben-reinventarse/414373-3

El museo de Troya. (2015, 11 de julio) Semana. Recuperado de http://www.semana.com/ cultura/articulo/discordia-en-el-museonacional/434378-3
Nietzsche, F. (2003). Sobre la utilidad y el perjuicio de la historia para la vida [II Intempestiva] (1874), Madrid: Biblioteca Nueva.

Nora, P. (1989). "Between Memory and History: Les Lieux de Mémoire”, en Representations No. 26, Special Issue: Memory and CounterMemory (Spring, 1989), University of California Press, p. 7-24.

Peláez, L. D. (2015). El museo de Troya [Fotografía]. Revista Semana. Recuperado de http://www.semana.com/cultura/articulo/ discordia-en-el-museo-nacional/434378-3

Ramos, C. \& V. Bernardez. (2009). "Usos y desusos de la historia en Nietzsche, Foucault y Benjamin”. V Jornadas de Jóvenes Investigadores, Buenos Aires, Instituto de Investigaciones Gino Germani, Facultad de Ciencias Sociales, Universidad de Buenos Aires.

Repensar el Museo Nacional de Colombia. (2015). Recuperado de http://www.museonacional. gov.co/sitio/renovacion/default.aspx

Richard, N. (2007). Fracturas de la memoria. Arte y pensamiento crítico, Buenos Aires: Siglo XXI Editores.

Sánchez, G. \& D. Meertens (1983) Bandoleros, gamonales y campesinos.

El caso de La Violencia en Colombia, Bogotá: El Áncora.

Sánchez, G. \& M. E. Wills. (Comp.) (2000). Museo, memoria y nación. Misión de los museos nacionales para los ciudadanos del futuro, Bogotá: Ministerio de Cultura, Museo Nacional de Colombia, PNUD, IEPRI, ICANH. 
Toro Vesga, M. A. (2014, 14 de diciembre). Sala ‘Memoria y nación’ del Museo Nacional, un tributo a la diversidad. El tiempo. Recuperado de http://www.eltiempo.com/ entretenimiento/arte-y-teatro/memoriay-nacion-la-nueva-sala-del-museonacional/14974082

Valencia, N. (2015). MGP + estudio.entresitio, primer lugar en concurso del futuro Museo Nacional de la Memoria de Colombia. ArchDaily. Recuperado de http://www. plataformaarquitectura.cl/cl/771771/mgparquitectura-y-urbanismo-primer-lugar-enconcurso-del-futuro-museo-nacional-de-lamemoria-de-colombia

Yerushalmi, Y. et al. (1998) Usos del Olvido, Segunda edición, Buenos Aires: Nueva Visión. 